\title{
AWARDS AS VALUE IMPERATIVES OF A STATE AND SOCIETY
}

\author{
Irina A. Bubnova \\ Moscow City University (MGPU), Moscow, Russia
}

\begin{abstract}
The article presents the results of a study on the texts and decrees on awarding and statutes of the highest orders of the USSR and modern Russia - the Order of Lenin and the Order of St. Andrew the First-Called. The purpose of the study was to identify the virtue imperatives that meet main goals of some stage in the state's development and transmit them through civil decorations in order to construe a sociocultural layer of a value picture of the world and, accordingly, to design a type of personality with a set of socially welcomed models of behavior, that is being in demand at a certain time period. The texts of decrees and statutes are analyzed with the reference to a method of content analysis, which resulted in distinction between the leading super-topical themes that are viewed as a reflection of a required public interest. Verification and clarification of the results was continued with a text compression method and conclusion on the virtue imperatives of both historical periods under study. In the USSR industrialization, ideological construction associated with the formation of moral excellence coordinates of the individual, the development of agriculture and science were (in descending order) of leading value, which in general corresponds to the main functions of the governmental institution. The leading virtue imperative of modern Russia is the sphere of ideology, meanwhile, reassessment of the value system is based primarily on samples of the Soviet past, which causes cognitive dissonance and can lead to unpredictable results.

Key words: sociolinguistics, value picture of the world, highest state awards, value imperatives, content analysis, text, text compression method, linguistic experiment.

Citation. Bubnova I.A. Awards as Value Imperatives of a State and Society. Vestnik Volgogradskogo gosudarstvennogo universiteta. Seriya 2. Yazykoznanie [Science Journal of Volgograd State University. Linguistics], 2019, vol. 18, no. 3, pp. 93-102. (in Russian). DOI: https://doi.org/10.15688/jvolsu2.2019.3.7
\end{abstract}

УДК 81 '27

ББК 81.006 .2
Дата поступления статьи: 10.03.2019

Дата принятия статьи: 28.08.2019

\section{НАГРАДЫ КАК ЦЕННОСТНЫЕ ИМПЕРАТИВЫ ГОСУДАРСТВА И ОБЩЕСТВА}

\author{
Ирина Александровна Бубнова \\ Московский городской университет (МГПУ), г. Москва, Россия
}

\begin{abstract}
Аннотация. В статье представлены результаты изучения текстов указов о награждении и статутов высших орденов СССР и современной России - ордена Ленина и ордена Святого апостола Андрея Первозванного. Основная задача исследования - выявление ценностных императивов государства, отвечающих главным целям конкретного этапа его развития, транслируемых через награды и направленных на формирование социокультурного плана ценностной картины мира и, соответственно, востребованного в данный историح ческий момент типа личности, следующего определенным социально одобряемым моделям поведения. 글 Тексты указов и статутов рассмотрены с применением контент-анализа с последующим выделением суперi тем, отражающих направленность государственных интересов. Верификация и уточнение результатов контент-анализа проведены в ходе эксперимента при помощи метода сжатия текста. Установлены ценностные б императивы СССР (по убыванию): индустриализация, идеологическое строительство, связанное с формированием системы смысложизненных координат личности, развитие сельского хозяйства и науки, что в целом сор соответствует основным функциям государства, обеспечивающим его существование. Главный ценностный императив современной России - идеология, при этом переформатирование системы ценностей опи-
\end{abstract}


рается на образцы советского прошлого, что вызывает состояние когнитивного диссонанса в обществе, результат которого непредсказуем.

Ключевые слова: социолингвистика, ценностная картина мира, высшие государственные награды, ценностные императивы, контент-анализ, текст, метод сжатия текста, лингвистический эксперимент.

Цитирование. Бубнова И. А. Награды как ценностные императивы государства и общества // Вестник Волгоградского государственного университета. Серия 2, Языкознание. - 2019. - T. 18, № 3. - С. 93-102. - DOI: https://doi.org/10.15688/jvolsu2.2019.3.7

\section{Введение}

Проблема ценностей, то есть тех морально-нравственных ориентиров, руководствуясь которыми выстраивает свою жизнь каждый член социума, была и остается актуальной для гуманитарных наук. Современная лингвистика не является исключением, так как только с помощью языка ценности становятся частью сознания личности, определяя ее деятельность и поведение. Для социолингвистики, которая сосредоточена на диаде «язык - общество», важны и изменения в языке, происходящие под влиянием внешних факторов [Крысин, 2004], так и ценностная картина мира [Карасик, 2004], в которой, помимо этнокультурной составляющей (по Ю.С. Степанову - культурных констант), выделяется и социокультурная составляющая [Карасик, 2004]. Она, по мнению В.И. Карасика, имеет непосредственное отношение к различным видам оценочных суждений, обусловленных в значительной мере идеологией (например, о собственности, смерти, труде, подвиге и т. д.), и передается через различные социальные институты. Вся их деятельность, несмотря на многообразие транслируемой в массовое сознание информации, подчинена одной важнейшей цели - формированию типа человека с определенной системой ценностей и моделями поведения, востребованными государством на каком-либо этапе его исторического развития [Карасик, 2004, c. 141]. Среди этих институтов есть те, чья функция регуляции жизнедеятельности общества сомнений не вызывает, например, средства массовой коммуникации, которые являются не просто чрезвычайно мобильной, но и универсальной системой координации, регламентации и управления процессами, протекающими в социуме. Роль других институтов в формировании стереотипизированных представлений личности о мире не столь очевидна, однако не менее значима. К таковым относится институт наград, позволяющий государству доносить до членов общества одобряемую и социально желательную модель поведения и эксплицировать таким образом наиболее важные для него ценностные императивы.

\section{Материал и методы исследования}

Материалом исследования послужили тексты указов о награждении высшими государственными наградами СССР и РФ - орденом Ленина и орденом Святого апостола Андрея Первозванного. В силу того, что количество получивших орден Ленина в СССР за время его существования составляет 431418 человек, мы ограничились периодом с 1930 (время учреждения первого типа ордена) по 1934 г. (появление второго типа ордена и связанное с этим изменение его статута). За этот промежуток времени данный орден вручался около 700 раз, доступной в открытых источниках является информация о 94 лицах и коллективах, удостоенных данной награды (Орден Ленина № 1-700). Тексты, содержащие эту информацию, и стали объектом предпринятого анализа. Орден Святого апостола Андрея Первозванного был восстановлен в 1998 году. С этого момента им были награждены 19 человек (Список кавалеров ордена Святого апостола Андрея Первозванного), причем последняя дата его вручения 28 марта 2019 года. Нами проанализированы все указы о награждении орденом Святого апостола Андрея Первозванного.

Предмет исследования - ценностные приоритеты государства, отраженные в критериях, являющихся основаниями для награждения высшими государственными наградами в СССР и Российской Федерации.

Основным методом установления критериев, эксплицирующих ценностные императивы, был избран контент-анализ [Григорьев, Растов, 2001], главное достоинство которого зак- 
лючается в возможности выделять в сплошном массиве анализируемых текстов отдельные темы, содержащие определенную идею, в нашем случае - маркер ценности.

При выделении тем - процедуре, обусловливающей валидность полученных результатов [Berelson, 1971; Krippendorff, 1980], - мы ориентировались на два основных вопроса, определяющих цель предпринятого исследования: 1) какие ценности транслировались через систему наград, то есть являлись приоритетными для государства в советский и постсоветский периоды его развития; 2) какими качествами личности должен обладать человек, чтобы быть достойным высшей государственной награды.

Отбор основных тем, представляющих собой аналитические категории / параметры анализа, осуществляся в ходе изучения текстов указов в соответствии с общепринятым алгоритмом. За единицу счета был принят отдельный текст указа, поэтому выделение данной единицы обусловливалось естественными границами рассматриваемых документов.

Полученные в результате осуществления эксперимента темы были универсализированы и сведены к нескольким супертемам, отражающим основные цели и, следовательно, доминирующие в изучаемый период развития страны ценности. Количественные подсчеты были дополнены качественной оценкой, что не только допускается самой процедурой контент-анализа, но и часто считается необходимым его этапом, поскольку сам метод направлен, по словам О.А. Леонтович, на обнаружение «как явного, эксплицитно выраженного, так и имплицируемого, латентного содержания, которое не имеет эксплицитных индикаторов и предполагает определенную долю интерпретации содержания» [Леонтович, 2011, с. 71]. Все это позволило решить основную задачу, поставленную в работе, - выявить доминирующие ценности и, соответственно, тип личности с определенными моделями поведения, основанными на ценностных ориентирах, рассматриваемых государством как предпочтительные.

С целью верификации и уточнения сделанных по результатам контент-анализа выводов был проведен пилотный психолингвистический эксперимент с использованием метода сжатия текста, отражающего одну из важнейших особенностей механизма речевой деятельности, состоящую, как отмечают исследователи, в выделении слушающим / читающим инвариантных языковых характеристик разных уровней значимости как основы для целесообразного восстановления всего текста с наибольшей точностью [Гинзбург, Пестова, Степанов, 1968]. Нами была избрана полностью отвечающая поставленным в работе задачам методика перифразы, предполагающая постепенную компрессию полного текста вплоть до ее предельного вида перифразы-свертывания, или набора ключевых слов, в ходе которой каждая из перифраз выступает как квазисиноним к исходному материалу, а сама методика оказывается, как было экспериментально доказано ее авторами [Сахарный, 1982; Сахарный, Штерн, 1988; Сиротко-Сибирский, Штерн, 1988], весьма эффективной при исследовании содержательной структуры развернутого текста.

Эксперимент проводился с использованием текстов статутов орденов Ленина (Орден Ленина - высшая государственная награда CCСР) и Святого апостола Андрея Первозванного (Государственные награды Российской Федерации), которые были предъявлены испытуемым с тремя заданиями, сформулированными следующим образом:

1. Напишите одно предложение так, чтобы оно передавало основное содержание статута ордена (размер предложения не ограничивается).

2. После выполнения первого задания напишите одно предложение, чтобы оно передавало основное содержание статута ордена, но в нем было бы не более 10 слов.

3. После выполнения второго задания выделите набор из 10 ключевых слов статута.

Общее количество участников эксперимента на данном этапе - 25 человек, все испытуемые - студенты вуза, средний возраст - 20 лет.

\section{Результаты и обсуждение}

\section{Орден Ленина}

В результате квантификации всего исследуемого массива текстов указов о награждении орденом Ленина было выделено 7 основных понятийно-тематических единиц, отража- 
ющих определенную направленность взглядов, интересов, ценностных ориентаций государства и, соответственно, норм деятельности и поведения личности, которые признавались достойными высшей награды (см. табл. 1, 2).

Качественный анализ индикаторов всех выделенных понятийно-тематических единиц позволяет свести их к нескольких супертемам, отражающим ценностные императивы государства: 1) государственное строительство, в том числе идеологическое, отражающее востребованную модель человека; 2) индустриализация; 3) сельскохозяйственное строительство; 4) научное строительство, необходимое прежде всего для укрепления обороноспособности страны, то есть защитой ее суверенитета, и здравоохранением, что обусловлено непосредственно созданием условий, обеспечивающих достойную жизнь человека, а следовательно, сохранение и увеличение населения страны и повышение качества его жизни (от- метим, что проведенный нами анализ указов о награждении Орденом Трудового Красного Знамени, касающийся государственных приоритетов в более ранний период его развития, показал, что научное строительство в тот временной промежуток в значительной степени было связано с образованием).

Важным, на наш взгляд, является и тот факт, что орденом Ленина был отмечен труд целых коллективов заводов и сельскохозяйственных предприятий, а при награждении отдельных лиц учитывался их личный вклад в развитие той или иной сферы. Например, Г.М. Крижижановского, вице-президента Академии наук СССР, наградили за непосредственную разработку и внедрение плана ГОЭЛРО, В.А. Кипрова и Н.И. Евсикова, красноармейцев-подрывников, - за самоотверженную, быструю и героическую работу в деле ликвидации пожара на Майкопских нефтяных промыслах, И.М. Губкина, вице-президента Академии

Таблица 1

\section{Ценностные императивы государства, отраженные в понятийно-тематических единицах}

\begin{tabular}{|c|c|}
\hline $\begin{array}{c}\text { Понятийно-тематические } \\
\text { единицы }\end{array}$ & Индикаторы понятийно-тематических единиц в текстах указов \\
\hline $\begin{array}{l}\text { Деятельность в непроизвод- } \\
\text { ственной сфере }\end{array}$ & строительство \\
\hline $\begin{array}{l}\text { Деятельность в сфере укреп- } \\
\text { ления государственности }\end{array}$ & $\begin{array}{l}\text { Организация братского содружества союзных республик, укрепление ра- } \\
\text { венства народов, населяющих СССР, улучшение и упрощение государст- } \\
\text { венного аппарата, приспособление государственного аппарата к задачам } \\
\text { строительства социализма, борьба с бюрократизмом, бесхозяйственностью } \\
\text { и безответственностью в советских и хозяйственных организациях, чистка } \\
\text { госаппарата }\end{array}$ \\
\hline $\begin{array}{l}\text { Деятельность по выполне- } \\
\text { нию поставленных планов в } \\
\text { промышленности и сельском } \\
\text { хозяйстве }\end{array}$ & $\begin{array}{l}\text { Выполнение пятилетки в 2,5 года, пятилетнего плана нефтяной промыш- } \\
\text { ленности в 2,5 года, обязательств перед государством }\end{array}$ \\
\hline $\begin{array}{l}\text { Деятельность в сфере ста- } \\
\text { новления и развития про- } \\
\text { мышленности }\end{array}$ & $\begin{array}{l}\text { Электрификация СССР, план ГОЭЛРО, восстановление и запуск заводов, } \\
\text { восстановление и реконструкция нефтяной промышленности, организация } \\
\text { с/х и строительства заводов комбайнов, налаживание массового производ- } \\
\text { ства с/х техники, особые выдающиеся заслуги в деле машиностроения }\end{array}$ \\
\hline $\begin{array}{l}\text { Деятельность в сфере ста- } \\
\text { новления и развития сель- } \\
\text { ского хозяйства }\end{array}$ & $\begin{array}{l}\text { Организация машинотракторных станций, обеспечение выполнения постав- } \\
\text { ленных в с/х задач, сев, уборка урожая, засыпка семян, укрепление колхозов } \\
\text { и совхозов }\end{array}$ \\
\hline $\begin{array}{l}\text { Деятельность в сфере науки, } \\
\text { в том числе освоения новых } \\
\text { территорий }\end{array}$ & $\begin{array}{l}\text { Разрешение исторической задачи сквозного плавания по Ледовитому океа- } \\
\text { ну в одну навигацию, выдающиеся заслуги в области медицины }\end{array}$ \\
\hline $\begin{array}{l}\text { Личностные характеристики } \\
\text { (модели поведения), прояв- } \\
\text { ленные в экстремальных си- } \\
\text { туациях }\end{array}$ & $\begin{array}{l}\text { Помощь, спасение, умелое использование достижений советской авиации, } \\
\text { обеспечение надежной работы моторов в перелетах на льдины, малоизучен- } \\
\text { ные условия Ледовитого океана, исключительно инициативная, четкая и } \\
\text { самоотверженная работа, беззаветная преданность, героическая деятель- } \\
\text { ность на благо Советского народа, Новая Земля, самоотверженность, быст- } \\
\text { рая и героическая работа, ликвидация пожара на Майкопских нефтяных } \\
\text { промыслах }\end{array}$ \\
\hline
\end{tabular}


И.А. Бубнова. Награды как ценностные императивы государства и общества

Таблица 2

Основания для награждения орденом Ленина

(в \% ко всем выделенным тематическим единицам)

\begin{tabular}{|c|c|c|}
\hline Понятийно-тематические единицы & Коллективы & $\begin{array}{c}\text { Отдельные } \\
\text { лица }\end{array}$ \\
\hline Деятельность в непроизводственной сфере & 1 & - \\
\hline Деятельность в сфере укрепления государственности & - & 2 \\
\hline $\begin{array}{l}\text { Деятельность по выполнению поставленных планов в } \\
\text { промышленности и сельском хозяйстве }\end{array}$ & 11 & 32 \\
\hline $\begin{array}{l}\text { Деятельность в сфере становления и развития промыш- } \\
\text { ленности }\end{array}$ & 2 & 14 \\
\hline $\begin{array}{l}\text { Деятельность в сфере становления и развития сельского } \\
\text { хозяйства }\end{array}$ & 7 & 1 \\
\hline $\begin{array}{l}\text { Деятельность в сфере науки, в том числе освоения но- } \\
\text { вых территорий }\end{array}$ & - & 7 \\
\hline $\begin{array}{l}\text { Личностные характеристики (модели поведения), про- } \\
\text { явленные в экстремальных ситуациях }\end{array}$ & - & 23 \\
\hline Bсего & 21 & 79 \\
\hline
\end{tabular}

наук СССР, - за работы в области нефтяной промышленности, О.Ю. Шмидта, начальника экспедиции на ледоколе «Александр Сибиряков», и других членов экспедиции - за успешное разрешение исторической задачи сквозного плавания по Ледовитому океану в одну навигацию и т. д.

В целом выделенные супертемы, служившие основанием для награждения орденом Ленина, соответствуют основным функциям государства, то есть важнейшим направлениям его деятельности: политической, экономической и социальной (внутренние), а также функции обороны страны (внешняя), в совокупности обеспечивающим само его существование (подробно о функциях государства см.: [Рыбаков, 2017]).

В результате эксперимента был получен трижды компрессированный текст статута.

Предложения, полученные в результате выполнения респондентами первого задания, в среднем состояли из 28 слов, самое длинное из них -36 , самое короткое - 16 . Типичные ответы на первое задание:

(1) Орден Ленина - это высшая награда СССР, которой награждаются граждане за исключительные заслуги перед государством, которые соответствуют ценностям СССР и направлены на развитие общества и дружбы народов.

(2) Орденом Ленина награждаются за особо важные заслуги и исключительные достижения перед советским государством и обществом, за выдающиеся деяние, совершенные на благо страны и общества
Предложения, полученные в результате выполнения респондентами второго задания, в среднем состояли из 12 слов, самое длинное из них -18 , самое короткое -7 . Типичные ответы:

(3) Орден Ленина давался за развитие и укрепление советского государства.

(4) Орден Ленина - высшая награда за исключительные достижения перед советским народом.

Очевидно, что и в первом, и во втором случаях компрессии подвергались разделы статута, в которых подробно перечисляются те, кто может быть награжден, и указывается, за что вручается данный орден. Поставленные в эксперименте жесткие ограничения на количество и длину предложений (во втором случае) проявились в том, что испытуемые, опуская детали, стремились обобщить все описанные в статуте действия, заслуживающие признания, делая вывод о наиболее важных для государства ценностях, достойных быть отмеченными наградой. При этом в подавляющем большинстве случаев оставлялось и упоминание о том, кому посвящены совершенные подвиги.

Ключевые слова, выделенные в результате выполнения третьего задания, также фиксируют три параметра: 1) кто награждается - граждане СССР, коллективы, предприятия, объединения, населенные пункты; 2) за какие заслуги, то есть ценности - укрепление, развитие, экономика, производство, (самоотверженный) труд, изобретение, защита (Отечества), обороноспособность, дружба, сотрудничество, мир, на- 
ука, культура, исключительные достижения, боевые действия, герой, революционное движение, сочиальный прогресс, рабоma; 3) заслуги перед кем - (сочиалистическое) Отечество, народ, (социалистическое) общество, советское государство, страна.

В целом сравнение супертем, выделенных в ходе контент-анализа указов о награждении, и данных, полученных в экспериментах по компрессии текста статута ордена Ленина, показывает, что они коррелируют, причем эксперимент эксплицировал связь между конкретными достижениями, которые отражают ценности государства, создающие основу для его существования и жизнеобеспечения: cmpouтельство и укрепление государства, развитие промышленности, сельского хозяйства, науки, транслируемые через наградную систему, и наградами, вручаемыми от имени всего народа его гражданам и коллективам.

\section{Орден Святого апостола Андрея Первозванного}

Основные понятийно-тематические единицы, выражающие ценностные императивы современной России и, следовательно, передающие требования государства к нормам поведения личности и системе ее ценностносмысловых ориентаций, достойным высшей государственной награды, которые были получены в результате квантификации текстов указов о награждении орденом Святого апостола Андрея Первозванного, отражены в таблицах 3, 4.

Особо интересен тот факт, что выделенные тематические единицы изначально совпадают с супертемами, отражающими ценностные императивы государства. Прежде всего это касается деятельности в непроизводственной сфере, которая, по своей сути, является сферой идеологии, что и отражается в индикаторах понятийно-тематических единиц: духовное и нравственное возрождение России, гражданская позиичи, общественная деятельность, культура и литерату$p a$, всегда относившихся именно к идеологическим инструментам. Примечательно также то, что индикаторы и имена награжденных, если оценивать эти параметры именно как сопряженные друг с другом, представляют собой взаимоотрицающие тезисы, иначе

Таблица 3

Ценностные императивы государства, отраженные в понятийно-тематических единицах

\begin{tabular}{|c|c|}
\hline $\begin{array}{l}\text { Понятийно-тематические } \\
\text { единицы }\end{array}$ & Индикаторы понятийно-тематических единиц в текстах указов \\
\hline $\begin{array}{l}\text { Деятельность в непроизвод- } \\
\text { ственной сфере, в том числе } \\
\text { в сфере культуры и литера- } \\
\text { туры }\end{array}$ & $\begin{array}{l}\text { Вклад в духовное и нравственное возрождение России, высокая гражданская } \\
\text { позиция, активная общественная деятельность, выдающийся вклад в разви- } \\
\text { тие отечественной и мировой музыкальной и хореографической культуры и } \\
\text { искусства, отечественной литературы, отечественной культуры }\end{array}$ \\
\hline $\begin{array}{l}\text { Государственная деятель- } \\
\text { ность }\end{array}$ & $\begin{array}{l}\text { Выдающиеся заслуги перед Отечеством, многолетняя плодотворная государ- } \\
\text { ственная деятельность }\end{array}$ \\
\hline $\begin{array}{l}\text { Деятельность в сфере внеш- } \\
\text { ней политики }\end{array}$ & $\begin{array}{l}\text { Выдающиеся заслуги в укреплении дружбы и сотрудничества между наро- } \\
\text { дами Российской Федерации и КНР, России и Азербайджана, личный вклад в } \\
\text { укрепление мира и дружбы между народами }\end{array}$ \\
\hline $\begin{array}{l}\text { Деятельность в сфере науки, } \\
\text { в том числе в ВПК }\end{array}$ & Выдающиеся достижения в области здравоохранения \\
\hline
\end{tabular}

Таблица 4

Основания для награждения орденом Святого апостола Андрея Первозванного (в \% ко всем выделенным тематическим единицам)

\begin{tabular}{|c|c|c|}
\hline Понятийно-тематические единицы & Коллективы & $\begin{array}{c}\text { Отдельные } \\
\text { лица }\end{array}$ \\
\hline Деятельность в непроизводственной сфере & - & 63 \\
\hline Государственная деятельность & - & 5 \\
\hline Деятельность в сфере внешней политики & - & 16 \\
\hline Деятельность в сфере науки, в том числе ВПК & - & 16 \\
\hline Bcezo & 0 & 100 \\
\hline
\end{tabular}


говоря, объекты, которые могут быть объединены между собой только в рамках аутистического мышления. Сам создатель учения об аутизме Э. Блейлер многократно отмечал, что аутизм «ставит на место одного понятия другое, имеющее при объективном рассмотрении лишь второстепенные общие компоненты с первым», при этом «перемешивает бесцеремонно настоящее, прошедшее и будущее $<$..> воспоминания, которые давно уже стали недоступны реалистическому мышлению, используются им как недавние, может быть, им даже отдается предпочтение, так как они меньше наталкиваются на противоречие с актуальностью» [Бейлер]. Другими словами, этот тип мышления заменяет реальность моделью, которая внешне вполне логична, презентабельна и, главное, вполне может использоваться в работе с массовым сознанием для решения определенных задач. В рассматриваемом нами случае парадокс заключается в том, что все (за исключением двух человек), кто получил высшую государственную награду за «духовное и нравственное возрождение России, активную гражданскую позицию», в советское время были награждены орденами и медалями СССР, причем также за вклад в идеологическое воспитание: лауреаты Сталинской и Ленинской премий и кавалеры ордена Ленина С.В. Михалков и Р.Г. Гамзатов, орденами Ленина, Красного Знамени и Трудового Красного Знамени были награждены Д.А. Гранин, И.К. Архипова, Д.С. Лихачев и другие кавалеры российского ордена Святого апостола Андрея Первозванного. Большинство из награжденных в период СССР носили звание Героя Социалистического Труда. Можно говорить о том, что с психолингвистических позиций язык указов и статута ордена является некогерентным, утверждения, высказываемые в этих текстах, не связываются в непротиворечивые умозаключения, и это не позволяет определить смысловое содержание ценности идеологического строительства, несмотря на то, что именно сегодня данная сфера деятельности, как показывает анализ, - приоритет государства.

Менее важной, если судить по количеству награжденных, представляется деятельность в сфере внешней политики и науки, причем, как и в предыдущем случае, награжден- ные за эти заслуги политические деятели занимали высшие должности в партийной иерархии в СССР, а академики Б.В. Петровский и В.И. Шумаков также были кавалерами ордена Ленина и Героями Социалистического Труда, и все их выдающиеся заслуги в области здравоохранения относятся к советскому периоду развития нашей страны.

Следует отметить, что выделяемые в ходе качественного анализа супертемы свидетельствуют о низкой значимости, второстепенности (если не полном отсутствии) ценностей, касающихся таких сфер, как промышленное и сельскохозяйственное производство, государственное строительство и укрепление суверенитета страны, что является скрытым показателем смены иерархии главных государственных функций и, соответственно, изменения основных государственных целей.

Компрессия текста статута ордена Святого апостола Андрея Первозванного, проведенная в ходе эксперимента трижды, дала следующие результаты.

Предложения, полученные в процессе выполнения респондентами первого задания, в среднем состояли из 17 слов, самое длинное из них -27 , самое короткое - 11 . Типичным был следующий ответ:

(5) Орденом Святого апостола Андрея Первозванного награждаются видные государственные деятели, выдающиеся представители разных сфер за исключительные заслуги перед Россией.

Предложения, полученные в результате выполнения респондентами второго задания, в среднем состояли из 8 слов, самое длинное из них -12 , самое короткое -6 , причем часто до $50 \%$ включенных в предложение слов являлись названием самого ордена. Типичный ответ:

(6) Орденом Святого Андрея Первозванного награждаются видные деятели.

В обоих случаях, в отличие от текста статута ордена Ленина, компрессии подвергся прежде всего раздел, касающийся лиц, которые могут быть награждены, в частности, фразы другие граждане Российской Федерации; главы и руководители правительств зарубежных государств, а также правила 
ношения ордена, которые оказались нерелевантными для респондентов. Что касается критериев награждения, то менее существенной деталью, которая была исключена, явились слова способствуюшие процветанию, величию и славе России.

Исключенные из перечня необходимых сведений в ходе компрессии текста статута при выполнении первых двух заданий, эти слова попадают в список ключевых как уточняющие смысл исключительных заслуг выдающихся государственных деятелей и, соответственно, отражающие декларируемые государством ценностные приоритеты: проиветание, величие, слава России, развитие международной дружбы. Однако большая часть ключевых слов относится к правилам ношения ордена и конкретизирует льготы, получаемые его кавалерами: иель, звезда, портрет, музей, (плечевая) лента, апостол, святой, вера, розетка, служба, государственный чин, мечи, кавалер, пенсия, то есть в фокус внимания респондентов попадает один из признаков тех, «кто награждается». Содержание этого признака расширяется за счет уточнения того, какие привилегии имеет награжденный.

В целом результаты, полученные в ходе компрессии текста статута, не дают основания утверждать, что через высшую государственную награду России - орден Святого апостола Андрея Первозванного - в сознание обычного гражданина страны передаются какие-либо ценности, которые могут стать основой для формирования определенной модели поведения. Можно предполагать, что объяснение такого положения, с одной стороны, лежит в области семантики слов проиветание, величие, слава, которые не только относятся к группе абстрактной лексики, но и не имеют определенного смысла и трактуются различными способами. Именно такие слова, как отмечал Г. Лебон, обнаруживают огромный манипулятивный потенциал и оказывают магическое воздействие на сознание [Лебон, Тард, 1998, с. 47]. Исходя из этого, можно было ожидать высокую степень вариативности реакций, отражающих смысловое содержание использованных в тексте статута слов для каждого респондента. Тем не менее наше предположение не подтвердилось: все полученные ответы представляли собой буквальное воспроизведение целой фразы, что позволяет усомниться в существовании связи между словами проиветание, величие, слава и современной Россией в сознании участников эксперимента. Однако такое допущение, безусловно, может рассматриваться лишь как гипотеза, требующая экспериментальной проверки.

\section{Выводы}

Проведенное исследование позволяет с высокой степенью уверенности утверждать слудеющее.

1. Ценностные императивы государства, транслируемые через высшие государственные награды, в советский и современный периоды его развития кардинально различаются.

2. В СССР (по крайней мере на раннем этапе его становления) орден Ленина вручался за самоотверженный (включая коллективный) труд, значительный вклад в становление и развитие промышленности, в том числе оборонной, сельского хозяйства, науки, решавшей задачи, которые определяли рост уровня жизни населения и безопасности границ, а также личное мужество и героизм, проявленные при выполнении задач государственной важности. Из этого следует, что основные ценности государства были связаны с ростом экономического потенциала и укреплением суверенитета страны. Немаловажным представляется и то обстоятельство, что все достижения, а также модели поведения кавалеров ордена Ленина использовались в сфере идеологического строительства, имплицитно очерчивая тот идеал человека, который был необходим государству.

3. В современной Российской Федерации единственным ценностным императивом является идеологическое строительство, именно эта ценность транслируется через высшую государственную награду - орден Святого апостола Андрея Первозванного. Однако формирование нового типа человека в силу отсутствия реальных образцов, подкрепляемых осязаемыми конкретными и признаваемыми общественным сознанием заслугами, опирается прежде всего на примеры советского прошлого. Такая ситуация не может не вызы- 
вать когнитивного диссонанса, и, соответственно, в данных условиях попытки социальных институтов переформатировать социокультурный план ценностной картины мира в сознании личности способны привести к непредсказуемым результатам.

\section{СПИСОК ЛИТЕРАТУРЫ}

Бейлер Э. Аутистическое мышление // Psychology Online.Net. URL: http://www.psychologyonline.net/articles/doc-70.html (дата обращения: 27.02.2019).

Гинзбург Е. Л., Пестова В. А., Степанов В. Г., 1968. Операции сжатия как средства форсированной реконструкции текста // Теория речевой деятельности (проблемы психолингвистики) / отв. ред. А. А. Леонтьев. М. : Наука. С. 101-104.

Григорьев С. И., Растов Ю. Е., 2001. Основы современной социологии. Барнаул : Изд-во Алт. гос. ун-та. 375 с.

Карасик В. И., 2004. Языковой круг: личность, концепты, дискурс. М. : Гнозис. 390 с.

Крысин Л. П., 2004. Русское слово, свое и чужое : Исследования по современному русскому языку и социолингвистике. М. : Яз. слав. культуры. 888 с.

Лебон Г., Тард Г., 1998. Психология толп. Мнение и толпа. М. : Ин-т психологии РАН : КСП+. 416 с.

Леонтович О. А., 2011. Методы коммуникативных исследований. М. : Гнозис. 224 с.

Рыбаков В. А., 2017. Функции государства: системный подход // Вестник Омского университета. Серия: Право. № 2 (51). С. 14-18.

Сахарный Л. В., 1982. Актуальное членение и компрессия текста (к использованию методов информатики в психолингвистике) // Теоретические аспекты деривации : межвуз. сб. науч. тр. / под ред. Л. Н. Мурзина. Пермь : Изд-во Перм. ун-та. С. 29-38.

Сахарный Л. В., Штерн А. С., 1988. Набор ключевых слов как тип текста // Психолингвистические аспекты в системе профессионально-ориентированного обучения иноязычной речевой деятельности : межвуз. сб. науч. тр. Пермь : Изд-во Перм. ун-та. С. 34-51.

Сиротко-Сибирский С. А., Штерн А. С., 1988. К измерению качества работы предметизатора // Предметный поиск в традиционных и нетрадиционных ИПС : сб. науч. тр. Вып. 8. C. 131-147.

Berelson B., 1971. Content Analysis in Communication Research. N.Y. : Hafner Publishing Company. 220 p.
Krippendorff K., 1980. Content Analysis: An Introduction to its Methodology. Beverly Hills, CA : Sage Publishers. 191 p.

\section{ИСТОЧНИКИ}

Государственные награды Российской Федерации. URL: http://www.award.gov.ru/andrey_order.html (дата обращения: 06.02.2019).

Ордена Ленина № 1-700. URL: http://www.medalsss.ru (дата обращения: 06.02.2019).

Орден Ленина - высшая государственная награда CCCP. URL: http://antiques-consulting.com/ orden-lenina-vysshaya-gosudarstvennayanagrada-sssr-opisanie-tipy-i-vidy.html (дата обращения: 06.02.2019).

Список кавалеров ордена Святого апостола Андрея Первозванного (Российская Федерация). URL: https://dic.academic.ru/dic.nsf/ruwiki/ 1511012 (дата обращения: 06.02.2019).

\section{REFERENCES}

Bleuler E. Autisticheskoe myshlenie [Autistic Thinking]. URL: http://www.psychologyonline.net/articles/doc-70.html (accessed 27 February 2019).

Ginzburg E.L., Pestova V.A., Stepanov V.G., 1968. Operatsii szhatiya kak sredstva forsirovannoy rekonstruktsii teksta [Shrink Operation as a Means of Accelerated Reconstruction of the Text]. Leontyev A.A., ed. Teoriya rechevoy deyatelnosti (problemy psikholingvistiki) [Theory of Speech Activity (Psycholinguistics Problems)]. Moscow, Nauka Publ., pp. 101-104.

Grigoryev S.I., Rastov Yu.E., 2001. Osnovy sovremennoy sotsiologii [Fundamentals of Modern Sociology]. Barnaul, Izd-vo Altayskogo gosudarstvennogo universiteta. $375 \mathrm{p}$.

Karasik V.I., 2004. Yazykovoy krug: lichnost, kontsepty, diskurs [Language Circle: Personality, Concepts, Discourse]. Moscow, Gnozis Publ. 390 p.

Krysin L.P., 2004. Russkoe slovo, svoe i chuzhoe: Issledovaniya po sovremennomu russkomu yazyku i sotsiolingvistike [The Russian Word in the Context of Native and Foreign Interpretation: Studies in the Modern Russian Language and Sociolinguistics]. Moscow, Yazyki slavyanskoy kultury. 888 p.

Lebon G., Tard G., 1998. Psikhologiya tolp. Mnenie $i$ tolpa [Crowd Psychology. Opinion and the Crowd]. Moscow, Institut psikhologii RAN, $\mathrm{KSP}+.416 \mathrm{p}$. 


\section{ГЛАВНАЯ ТЕМА НОМЕРА}

Leontovich O.A., 2011. Metody kommunikativnykh issledovaniy [Methods of Communicative Research]. Moscow, Gnozis Publ. 224 p.

Rybakov V.A., 2017. Funktsii gosudarstva: sistemnyy podkhod [The Functions of the State: System Approach]. Vestnik Omskogo universiteta Seriya: Pravo [Herald of Omsk University. Series: Law], no. 2 (51), pp. 14-18.

Sakharnyy L.V., 1982. Aktualnoe chlenenie i kompressiya teksta ( $\mathrm{k}$ ispolzovaniyu metodov informatiki v psikholingvistike) [Actual Segmentation and Text Compression (To the Use of Computer Science Methods in Psycholinguistics)]. Murzin L.N., ed. Teoreticheskie aspekty derivatsii : mezhvuz. sb. nauch. tr. [Theoretical Aspects of Derivation. Interunivercity Collection of Scientific Papers]. Perm, Izd-vo Permskogo universiteta, pp. 29-38. Sakharnyy L.V, Shtern A.S., 1988. Nabor klyuchevykh slov kak tip teksta [Keyword Set as Text Type]. Psikholingvisticheskie aspekty $v$ sisteme professionalno-orientirovannogo obucheniya inoyazychnoy rechevoy deyatelnosti: mezhvuz. sb. nauch. tr. [Psycholinguistic Aspects in the System of Vocational-Oriented Learning of Foreign Language Speech Activity. Interunivercity Collection of Scientific Papers]. Perm, Izd-vo Permskogo universiteta, pp. 34-51.

Sirotko-Sibirskiy S.A., Shtern A.S., 1988. K izmereniyu kachestva raboty predmetizatora [On Measuring the Quality of the Work of the Prefabricator]. Predmetnyy poisk $v$ traditsionnykh $i$ netraditsionnykh IPS: $s b$. nauch. tr. [Object Search in Traditional and Non-Traditional IPS. Collection of Scientific Papers], iss. 8, pp. 131-147.

Berelson B., 1971. Content Analysis in Communication Research. New York, Hafner Publishing Company. $220 \mathrm{p}$.

Krippendorff K., 1980. Content Analysis: An Introduction to Its Methodology. Beverly Hills, CA, Sage Publishers. 191 p.

\section{SOURCES}

Gosudarstvennye nagrady Rossiyskoy Federatsii [State Awards of the Russian Federation]. URL: http://www.award.gov.ru/andrey_order.html (accessed 6 February 2019).

Ordena Lenina № 1-700 [Order of Lenin no. 1-700]. URL: http://www.medal-sss.ru/ (accessed 6 February 2019).

Orden Lenina - vysshaya gosudarstvennaya nagrada SSSR [Order of Lenin - The Highest State Award of the USSR]. URL: http://antiquesconsulting.com/orden-lenina-vysshayagosudarstvennaya-nagrada-sssr-opisanie-tipyi-vidy.html (accessed 6 February 2019).

Spisok kavalerov ordena Svyatogo apostola Andreya Pervozvannogo (Rossiyskaya Federatsiya) [List of Recipients of the Order of Saint Andrew the Apostle the First-Called (Russian Federation)]. URL: https://dic. academic.ru/dic.nsf/ruwiki/1511012 (accessed 6 February 2019).

\section{Information about the Author}

Irina A. Bubnova, Doctor of Sciences (Philology), Professor, Head of Foreign Philology Department, Moscow City University (MGPU), 2 Selskokhozyaystvennyy Proezd, 4, 129226 Moscow, Russia, aribubnova@gmail.com, https://orcid.org/0000-0002-1024-600X

\section{Информация об авторе}

Ирина Александровна Бубъова, доктор филологических наук, профессор, заведующая кафедрой зарубежной филологии, Московский городской университет (МГПУ), 2-й Сельскохозяйственный проезд, 4, 129226 г. Москва, Россия, aribubnova@gmail.com, https:/orcid.org/0000-0002-1024-600X 